\title{
Quem é Bom (e Eu Gosto) é Bonito: Efeitos da Familiaridade na Percepção de Atratividade Física em Pré-Escolares
}

\author{
Cristina Landgraf Lee-Manoel ${ }^{12}$ \\ Maria de Lima Salum e Morais \\ Vera Silvia Raad Bussab \\ Emma Otta \\ Universidade de São Paulo
}

\begin{abstract}
Resumo
O estudo procurou determinar a relação entre julgamentos de atratividade física, indicadores sociométricos e atributos comportamentais em pré-escolares. A atratividade das crianças foi avaliada por três adultas familiarizadas com elas, por três adultas que não as conheciam, por seus colegas e por elas próprias. Foram apuradas as escolhas positivas e negativas que cada criança recebeu. As crianças julgaram o comportamento dos colegas dentro de quatro dimensões: alegre/ triste; agressivo/ não agressivo; sociável/ isolado; colaborador/ perturbador. Para avaliar a autopercepção das crianças, aplicou-se a Escala Ilustrada de Competência e Aceitação Social Percebidas para Crianças. Encontraram-se correlações significativas entre a avaliação de atratividade física segundo adultas familiarizadas e segundo os colegas com escolhas positivas e com atributos comportamentais pró-sociais. Os resultados denotam ligações entre afeto, julgamento de atratividade e avaliações comportamentais bem estabelecidas em crianças de 5 anos, indicando que o efeito do estereótipo torna-se menor à medida que aumenta o grau de informação sobre a pessoa que está sendo julgada.

Palavras-chave: Atratividade física; escolhas sociométricas; características comportamentais; auto-percepção.
\end{abstract}

Who is Good (and I Like) is Beautiful: Effects of Familiarity on Preschoolers' Perception of Physical Attractiveness

\begin{abstract}
This study examined the correlation between preschool judgements of physical attractiveness, sociometric choices and behavioral descriptions of peers. Children's physical attractiveness was evaluated by three adults acquainted with the children, three not acquainted with the children, peers and by the children themselves. Peer's behavioral descriptions were related to: sadness/ happiness; aggression/ not aggression; sociability/ withdrawal; and cooperation/ disturbance. The Pictorial Scale of Perceived Competence and Social Acceptance was administered in order to evaluate children's self-perception. Significant correlations between adults acquainted with the children and peer's evaluations of physical attractiveness and sociometric choices and prosocial behavioral descriptions were found. Results suggest well established connections among affect, physical attractiveness judgements and behavioral descriptions in 5 years old, showing that the stereotype effect decreases as the degree of information about the judged target increases.

Keywords: Physical attractiveness; preference by peers; behavioural characteristics; self-perception.
\end{abstract}

Os julgamentos interpessoais são freqüentemente influenciados por estereótipos. Esses, independentemente de estarem certos ou errados, fazem parte de um processo humano inevitável, constituindo-se numa espécie de atalho para avaliar as pessoas quando ainda não se dispõe de muitas informações sobre elas (Andersen, 1999). De acordo com a teoria da redução de incerteza, é elevada a motivação num encontro inicial para aumentar

\footnotetext{
1 Endereço para correspondência: Departamento de Psicologia Experimental do Instituto de Psicologia da USP, Av. Prof. Mello Moraes, 1721, 05508-900, São Paulo, S.P. Fone: (11) 3091-4448, Fax (11) 3091-4909. E-mail:vsbussab@usp.br; emmaotta@usp.br; crislee@usp.br

${ }^{2}$ Esta pesquisa foi subvencionada pelo CNPq. Agradecemos às crianças e funcionários da creche cuja participação tornou possível a realização deste estudo.
}

a certeza (Berger \& Calabrese, 1975) e, para isso, tendemos a utilizar qualquer pista informativa possível. Nesse sentido, a aparência física é fonte primária de informações durante uma interação inicial.

Adeptos da teoria da personalidade implícita (implicit personality theory) sugerem que as pessoas fazem inferências a respeito das outras com base em poucas características centrais (Schneider, 1973). Os julgamentos são feitos com base em informações limitadas. Predicados tidos como negativos têm efeito de sensibilizar os indivíduos para tirarem conclusões negativas sobre um conjunto de outros atributos ou traços da pessoa que está em julgamento; o oposto ocorre com predicados considerados positivos (Brown, 1986). A primeira impressão de uma pessoa pode ser bastante resistente a mudanças (Chia, Allred, Grossnickle \& Lee, 1998). 
Dion, Berscheid e Walster (1972) cunharam a expressão "quem é bonito é bom" para designar a tendência a atribuir diversas características positivas - como inteligência, sociabilidade e sucesso ocupacional - a pessoas consideradas atraentes, em detrimento daquelas apreciadas como pouco atraentes. Vinte anos depois desse artigo paradigmático, uma meta-análise feita por Feingold (1992), com base em 78 pesquisas que procuraram identificar os traços consistentemente associados à atratividade física, mostrou que pessoas tidas como atraentes são percebidas como mais sociáveis, dominantes, sexualmente calorosas, mentalmente saudáveis e socialmente habilidosas do que as vistas como pouco atraentes. Embora muitas provas atestem a existência da norma que diz "o que é belo é bom", a atratividade física também pode ser associada a alguns traços indesejáveis, como vaidade, egoísmo e maior tendência a ter problemas conjugais (Dermer \& Thiel, 1975; Wheeler \& Kim, 1997). Esses trabalhos referem-se às primeiras impressões, em que juizes que não conhecem as pessoas atribuem a elas, através de fotos, características sócio-afetivas. Entretanto, à medida que as pessoas se familiarizam com as outras, existe a possibilidade de que características positivas afetem o julgamento de atratividade, criando o efeito "quem é bom é bonito". Desconhecem-se estudos que tenham abordado essa problemática, principalmente considerando-se as avaliações de crianças.

O estereótipo da atratividade física também está presente nas impressões formadas por professores a respeito dos seus alunos. Crianças consideradas atraentes tendem a ser vistas como socialmente mais competentes, mais inteligentes e com maior potencial educacional em comparação com as julgadas pouco atraentes (Knapp \& Hall, 1972/1999). Entretanto, na meta-análise de Feingold (1992), não se verificaram relações notáveis entre atratividade física e traços de personalidade como a sociabilidade, a dominância, a saúde mental e outros, com exceção de alguns atributos relacionados ao comportamento social.

Estudos com crianças têm demonstrado que atratividade física e popularidade estão correlacionadas (Coie, Dodge \& Coppotelli, 1982; Kleck, Richardson \& Ronald, 1974; Langlois \& Stephan, 1977). A popularidade e a aceitação social podem ser medidas através de técnicas sociométricas de escolha. Num trabalho que trouxe contribuições fundamentais para a área, Coie e colaboradores (1982) propõem duas medidas - preferência social e impacto social - derivadas de respostas das crianças a duas questões simples: "de que colega(s) você gosta mais?" e "de que colega(s) você gosta menos"? Assim como o trabalho de Coie e colaboradores (1982), outros estudos têm apontado para o risco que sofrem as crianças com baixos índices de escolhas positivas e altos escores de escolhas negativas de desenvolver problemas de ajustamento social atual e futuro (Attili,1990; Furnham,1989; Hatzichristou \& Hopf, 1996; Parke \& cols., 1997; Rubin, 1990). Se a falta de atratividade física está relacionada à rejeição social, a aparência física da criança pode ser considerada um fator de risco (quando não é considerada boa), ou de proteção (quando é julgada boa) no desenvolvimento. De fato, comportamentos anti-sociais são avaliados com maior tolerância e considerados temporários quando apresentados por crianças tidas como atraentes. $\mathrm{O}$ mesmo ato apresentado por crianças vistas como pouco atraentes, além de mais grave, é considerado um traço permanente (Adams \& Crane, 1980; Cavior \& Howard, 1973; Dion, 1972, 1974). Não apenas os professores parecem interagir menos (e de maneira menos positiva) com a criança julgada sem atrativos na escola de ensino fundamental, mas também seus companheiros reagem a ela de forma desfavorável (Knapp \& Hall, 1972/1999).

Os julgamentos da aparência física são determinados por uma série de fatores além da mera harmonia e equilibrio dos traços fisionômicos. Dentre os parâmetros em que se baseiam as pessoas em sua apreciação do aspecto exterior de outras, encontram-se também a forma e proporção do corpo (Queiroz \& Otta, 1999), a maneira de se vestir, de gestualizar (Andersen, 1999), a higiene e cuidados corporais e o quanto o conjunto e composição de traços faciais aproximam-se do ideal de beleza de determinada cultura, o que nos remete à cor/raça/etnia da pessoa que está sendo avaliada. Assim, é importante que se considere essa variável na investigação da atratividade.

A base teórica que tem sido proposta para explicar possíveis diferenças entre pessoas consideradas atraentes e não atraentes tem sido o modelo da expectativa. Rosenthal e Jacobson (1968) levantaram questionamentos a respeito das possíveis conseqüências das expectativas de professores a respeito de seus alunos. Quando os professores foram induzidos a acreditar que alguns alunos seriam mais adiantados na aprendizagem, descobriu-se que as expectativas funcionavam como profecia auto-realizadora, ou seja, a profecia tendia a realizar-se. O trabalho de Rosenthal e Jacobson foi de importância fundamental para motivar pesquisas sobre os estereótipos, que são expectativas que ocorrem automaticamente, sem reflexão, e podem resultar no mesmo fenômeno produzido por expectativas geradas experimentalmente. Características socialmente apreciadas têm sido mais freqüentemente associadas a indivíduos atraentes, implicando em um efeito de halo da atratividade - o que vale dizer que "o bonito é bom". A existência desse estereótipo associando a beleza a valores pessoais sugere que pessoas percebidas como atraentes podem desenvolver qualidades desejáveis em resposta às expectativas dos outros. 
O mecanismo pelo qual as expectativas baseadas no estereótipo podem influenciar o desenvolvimento da personalidade tem sido pouco discutido. Uma hipótese para a explicação do fenômeno é via efeito da expectativa sobre o autoconceito (Darley \& Fazio, 1980). Por exemplo, se a expectativa em relação a um indivíduo é de que ele seja sociável, o comportamento dos outros pode influenciá-lo para que ele se torne uma pessoa sociável, induzindo-o gradualmente a internalizar a sociabilidade como parte de seu autoconceito e a se comportar de acordo com sua autoimagem. A autopercepção de atratividade seria influenciada pela auto-estima global, de tal forma que pessoas que têm uma auto-estima elevada também se sentiriam fisicamente atraentes.

A representação positiva do eu é um indicador crítico do bem-estar e de satisfação pessoal e fator essencial para o funcionamento eficaz da criança e do adulto (Mussen, Conger \& Kagan, 1973; Verschueren \& Marcoen, 1999). Utilizamos no presente estudo medidas de auto-avaliação de competência e de aceitação social (Harter \& Pike, 1983), bem como de características comportamentais e de atratividade física. Franco e Levitt (1998) sintetizam uma série de estudos que mostram a função do apoio social na proteção da auto-estima. Segundo Harter (1999), o apoio, na forma de aceitação e aprovação dos pais - e não dos companheiros -, é uma fonte importante de auto-avaliação para crianças pequenas, enquanto, para as mais velhas, a aprovação dos companheiros é a que mais contribui para sustentar o autoconceito. Entretanto, como Mussen e colaboradores (1973) relatam, a imagem que a criança tem de si influi na maneira como os companheiros reagem a ela.

Embora haja evidências no sentido de que um autoconceito positivo seja mais influenciado pelo suporte familiar em crianças de quatro a cinco anos, interessounos examinar a relação entre autopercepção e avaliação de atratividade física, pois supomos que, mesmo antes dessa idade, os companheiros se tornam, além dos adultos, importantes elementos de referência de aceitação social. Uma vez que os companheiros fornecem experiências únicas para o desenvolvimento de habilidades de interação e que algumas crianças podem sobressair na competência social refletida em suas relações com os colegas, podemos esperar relações positivas entre autoconceito e aceitação social e entre auto-avaliação positiva e atratividade física.

Outra questão importante é determinar o quanto o estereótipo se mantém após o primeiro contato, ou se modifica à medida que o conhecimento mútuo se aprofunda. Os resultados de pesquisas que fizeram essa indagação apontam em ambas as direções. Um aspecto relacionado diz respeito à interação entre julgamentos de atratividade física e de atributos comportamentais, tais como espontaneidade, alegria, sociabilidade, agressividade. Podemos a esse respeito levantar duas suposições: (1) características comportamentais positivas compensariam uma baixa atratividade física e atributos negativos anulariam uma alta atratividade; (2) a força do estereótipo seria tão grande que o julgamento inicial de atratividade física poderia, através de um processo de profecia autorealizadora - em larga medida inconsciente - determinar a concretização da expectativa inicial de tal forma que as pessoas consideradas pouco atraentes teriam menor possibilidade de mostrar suas eventuais características positivas. Embora essas hipóteses não possam ser testadas diretamente através de estudos correlacionais, que não possibilitam determinar a relação de causa-efeito, procuramos no presente trabalho averiguar se características comportamentais estão, de alguma forma, relacionadas à percepção de atratividade. A atratividade tem sido muito estudada, como demonstram duas meta-análises (Eagly, Ashmore, Makhijani \& Longo, 1991; Feingold, 1992). Entretanto, nos poucos estudos realizados na área de desenvolvimento infantil que investigaram a questão, a atratividade física tem sido considerada como uma das características comportamentais desejáveis e não manipulada como variável independente, da forma que nos propusemos a fazer na presente investigação. Para isso, levantamos as impressões iniciais de diversos juízes adultos familiarizados e não familiarizados com as crianças, as avaliações de colegas e da própria criança.

De forma sintética, os objetivos que nortearam o presente trabalho foram: (1) investigar relações entre as escolhas sociométricas de pré-escolares, as características comportamentais atribuídas pelos colegas e as classificações de atratividade física de diferentes juizes e (2) averiguar como se relacionam os julgamento de atratividade física por parte de avaliadores com diferentes graus de familiarização com as crianças e se as avaliações de diferentes juizes estão associadas ao autoconceito das crianças.

\section{Método}

\section{Participantes}

Foram estudadas 40 crianças com 5 anos de idade em média (variando de 4 anos e meio a 5 anos e meio), 17 meninas e 23 meninos, de diversas classes sociais (com base em arquivos da escola), que freqüentavam uma creche pública na cidade de São Paulo.

Todas as crianças tiveram a sua participação na pesquisa consentida pela direção da escola e por seus respectivos responsáveis legais, através de carta em que assumimos o compromisso de utilizar os dados exclusivamente para fins de pesquisa, seguindo os padrões éticos vigentes, e 
garantindo que, em nenhum momento, divulgaríamos a identidade das crianças.

Como a avaliação de raça é uma questão extremamente complexa, especialmente em países como o Brasil em que a diversidade e miscigenação de etnias é considerável (Guimarães, 2000), optamos por solicitar a três juízas de nível universitário, que se consideraram brancas e a três juízas do mesmo nível de instrução, que se avaliaram como pretas ou pardas que julgassem a cor das crianças através de fotos, segundo os critérios do IBGE (branca, preta, parda, amarela, outra). Como a correlação de Pearson entre as juízas brancas e pretas/pardas foi muito alta $(r=0,892 ; p<0,001)$, optouse por categorizar as crianças de acordo com a classificação predominante no conjunto dos seis julgamentos. Ao final, 24 crianças foram consideradas brancas (62\%), 14 pretas ou pardas $(36 \%)$ e uma, amarela $(2 \%)$.

O total de crianças avaliadas pelos adultos não familiarizados foi 39 crianças, pois não conseguimos fotografar um dos participantes que deixou de comparecer à creche no final do estudo.

\section{Procedimento}

\section{Avaliação de Atratividade Física}

As crianças foram avaliadas quanto à atratividade física por três observadoras adultas que conviveram com elas durante 4 meses, coletando dados para esta e outras pesquisas e por três juízas também adultas que não as conheciam. Esse último grupo avaliou-as através de um par de fotografias de cada criança, contendo uma foto dela séria e outra, sorrindo. As fotografias foram tiradas no mesmo local, no pátio da creche e repetidas caso a criança não se mostrasse muito à vontade. As juízas eram mulheres adultas, brancas e com nível universitário. A escala utilizada pelos dois grupos se baseava nas seguintes categorias: 1- Nada atraente; 2- Pouco atraente; 3- Medianamente atraente; 4- Atraente; 5- Muito atraente. Para possibilitar um agrupamento das crianças em três categorias, distribuíram-se os cinco escores em três grupos: pouco atraente (valores médios dos escores dos três juízes: de 1,0 a 2,99), medianamente atraente (valores médios dos escores dos três juízes: de 3,00 a 3,99) e muito atraente (valores médios dos escores dos três juízes: de 4,0 a 5,0). A porcentagem de crianças incluídas em cada categoria encontra-se na Tabela 1.

As crianças também foram avaliadas pelos próprios colegas, pedindo-se que nomeassem o colega que consideravam mais bonito e o menos bonito, ao final de entrevistas individuais em que foram feitos julgamentos de atributos comportamentais (descritos a seguir). Cada criança obteve um escore correspondente ao número de vezes que foi citada em cada categoria.

Por fim, foram realizadas auto-avaliações em que as crianças puderam manifestar-se a respeito da própria atratividade física, escolhendo uma de três possibilidades: não atraente, mais ou menos ou muito atraente. Os participantes se julgaram apenas muito atraentes ou medianamente atraentes. Foram computadas as avaliações de 35 participantes, pois quatro deles não compareceram à creche no período da respectiva coleta de dados e um disse não saber classificar-se.

\section{Avaliação de Preferência Social: Índices Sociométricos}

Perguntava-se a cada criança: "qual o (a) colega de quem você mais gosta?”. Em seguida, acrescentava-se: "e depois deste (a), de quem você mais gosta?". Depois da segunda citação, a última pergunta era repetida, até que se obtivessem os três colegas de quem o (a) participante mais gostava. Perguntava-se, então: "agora, me diga qual o (a) colega de quem você menos gosta" e repetia-se o procedimento até se obterem as três escolhas negativas. As crianças, em geral, tiveram maior dificuldade em citar os colegas de quem menos gostavam. Alguns participantes citaram apenas um ou dois nomes de companheiros de que mais ou de que menos gostavam, declarando não haver mais nenhuma criança naquela condição. Nesses casos, foram computados apenas os colegas citados. Foram computadas as escolhas negativas e positivas que cada criança recebeu, obtendo-se o escore de preferência social que é o resultado da subtração das escolhas negativas das positivas.

Tabela 1

Porcentagem de Crianças Incluidas nas Diversas Categorias de Atratividade Segundo Diferentes Juizes

\begin{tabular}{lccc}
\hline Juiz/avaliação & $\begin{array}{c}\text { Muito } \\
\text { atraente }\end{array}$ & $\begin{array}{c}\text { Medianamente } \\
\text { atraente }\end{array}$ & $\begin{array}{c}\text { Pouco } \\
\text { atraente }\end{array}$ \\
\hline Adulto familiarizado & 35 & 37,5 & 27,5 \\
Adulto não familiarizado & 25,6 & 53,8 & 20,5 \\
Colega & 27,5 & 52,5 & 20 \\
Auto-avaliação & 65,7 & 34,3 & 0 \\
\hline
\end{tabular}




\section{Avaliação de Competência e Aceitação Percebidas}

Adotamos a Escala Ilustrada de Competência e Aceitação Social Percebidas para Crianças (EICASP), desenvolvida por Harter e Pike (1983). Essas autoras criaram quatro escalas que avaliam: Competência Cognitiva (Ex.: saber fazer um quebra-cabeça), Competência Física (Ex.: escalar trepa-trepa), Aceitação por Companheiros (Ex.: ter muitos amigos) e Aceitação pela Figura Materna (Ex.: mãe que brinca com a criança).

Para cada item havia um par de figuras, ilustrando uma criança mais e outra menos competente em um dado atributo. O participante devia escolher a figura da criança do par que achava mais parecida consigo mesmo. A seguir, ele avaliava se a criança da figura escolhida era muito ou pouco parecida consigo mesmo. Os examinadores atribuíram um escore de 1 a 4 para cada item: 1 - Escolha da figura menos competente com círculo maior (muito parecida); 2 -Figura menos competente com círculo menor (pouco parecida); 3 - Figura mais competente com círculo menor (pouco parecida); 4 - Figura mais competente com círculo maior (muito parecida). Portanto, 4 era o escore máximo da criança que se achava muito competente em determinado atributo. Ao final, obteve-se uma pontuação média para cada escala e um escore médio total para cada participante. Foram utilizados dois conjuntos de pranchas: um para meninas e outro para meninos.

\section{Avaliação de Atributos Comportamentais}

As crianças foram também avaliadas pelos colegas quanto a atributos comportamentais. Para isto, utilizou-se um instrumento, adaptado a partir de Morais, Otta e Scala (2001), composto por quatro pranchas com figuras de crianças que ilustravam diferentes características comportamentais: ajuda/atrapalha, briga/não briga, alegre/ triste e sociável/não sociável. Cada prancha ilustrava à esquerda uma das ações, como "ajuda os colegas", sendo realizada por meninos e meninas e à direita, a ação antagônica correspondente, como "atrapalha os companheiros", também realizada por meninos e meninas. Exibiu-se primeiro a parte esquerda da prancha, fazendo-se, por exemplo, o comentário: "Estas crianças ajudam os outros. Qual o/a colega seu/sua que se parece com elas? (ou 'quem na sua classe é assim?')." Repetiu-se o procedimento para as oito características investigadas. Cada criança recebeu um escore da freqüência em que foi citada em cada característica.

Ao final da entrevista, cada criança foi lembrada a respeito da confidencialidade das respostas e pediu-se para que ela não discutisse a entrevista com os colegas.

\section{Resultados}

Correlação entre Avaliações de Atratividade Fisica por Parte de Adultos, de Colegas e da Própria Criança

A Tabela 2 mostra a correlação entre indicadores de atratividade calculados a partir das avaliações feitas por adultos familiarizados e não familiarizados e pelos colegas. Encontrou-se correlação positiva significativa entre as avaliações dos adultos familiarizados e aquelas dos não familiarizados. Apesar desse resultado, constatou-se diferença entre as avaliações dos dois grupos de adultos e aquelas do grupo de colegas; apenas os índices dos adultos familiarizados correlacionaram-se de modo significativo com os índices das crianças. Em vista disso, optamos por fazer análises distintas para os dois grupos de adultos (familiarizados e não familiarizados com as crianças). Os demais resultados significativos eram esperados, pois decorrem da fórmula de cálculo do índice de atratividade (número de indicações como atraente menos o número de indicações como não atraente); sendo assim, a avaliação dos colegas como atraentes e o índice de atratividade correlacionaram-se positivamente e houve correlação negativa entre avaliação dos colegas como não atraentes e o índice de atratividade.

Tabela 2

Correlação entre Indicadores de Atratividade

\begin{tabular}{|c|c|c|c|c|c|c|}
\hline Indicadores de Atratividade & 1 & 2 & 3 & 4 & 5 & 6 \\
\hline Avaliação por adultos familiarizados & 1,000 & & & & & \\
\hline Avaliação por adultos não familiarizados & $0,485^{* *}$ & 1,000 & & & & \\
\hline Avaliação por colegas como atraente & 0,231 & 0,190 & 1,000 & & & \\
\hline Avaliação por colegas como não atraente & $-0,201$ & 0,013 & 0,075 & 1,000 & & \\
\hline $\begin{array}{l}\text { Índice de atratividade a partir da avaliação por } \\
\text { colegas }(5=3-4)\end{array}$ & $0,318^{*}$ & 0,134 & $0,705^{* *}$ & $-0,654^{* *}$ & 1,000 & \\
\hline Avaliação pela própria criança & 0,115 & $-0,054$ & 0,145 & 0,283 & $-0,091$ & 1,000 \\
\hline
\end{tabular}

$* p<0,05 ; * * p<0,01$ 


\section{Escolhas Sociométricas em Função de Atratividade Física \\ Atratividade Avaliada por Adultos}

a) Não familiarizados com as crianças

$O$ teste de MANOVA não revelou efeitos estatisticamente significativos de sexo, nem de categorias de atratividade física, conforme julgamento por parte de adultos não familiarizados com as crianças sobre os indicadores sociométricos.

\section{b) Familiarizados com as crianças}

O teste de MANOVA revelou diferença global significativa dos indicadores sociométricos obtidos pelo julgamento dos colegas em função das categorias de atratividade física avaliada pelos adultos a elas familiarizados, Lambda de Wilks $=0,582, F(4,66)=5,124, p<0,01$. Testes univariados subseqüentes revelaram diferenças significativas quanto a escolhas positivas, $F(2,34)=6,143, p<0,01$, escolhas negativas, $F(2,34)=4,124, p<0,05$ e preferência social $F(2,34)=10,067, p<0,001$. Comparações dois-adois através do teste de Tukey revelaram que as crianças consideradas pouco atraentes foram alvo de um menor número de escolhas positivas, $p<0,01$, maior número de escolhas negativas, $p<0,05$, e tiveram escores de preferência social mais baixos, $p<0,001$, em comparação com as tidas como muito atraentes. As crianças consideradas medianamente atraentes foram alvo de um menor número de escolhas positivas, $p<0,05$, do que as avaliadas como muito atraentes. Quando comparadas com as vistas como pouco atraentes, as consideradas medianamente atraentes receberam menos escolhas negativas e tiveram maior escore de preferência social $(p<0,05)$. A Figura 1 representa as médias dos índices sociométricos em função de atratividade conforme avaliação de adultos familiarizados com as crianças.

O teste de MANOVA não revelou efeito global significativo de sexo, nem de interação entre sexo e categorias de atratividade física.

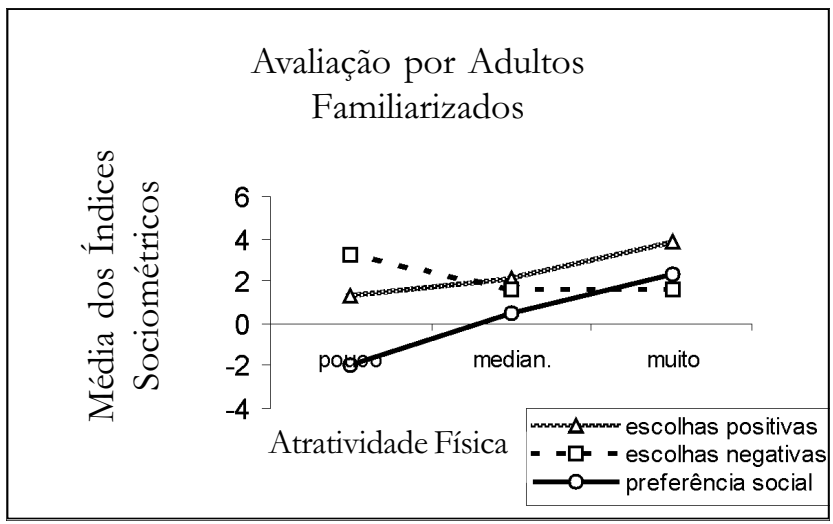

Figura 1. Índices sociométricos em função de atratividade física avaliada por adultos familiarizados.

\section{Atratividade Avaliada pelos Colegas}

O teste de MANOVA revelou diferença global significativa dos indicadores sociométricos em função das categorias de atratividade física avaliada pelos colegas ( L ambda de Wilks $\left.=0,624, F_{4,66}=4,386, p<0,01\right)$. Testes univariados subseqüentes revelaram diferenças significativas quanto a escolhas positivas $\left(F_{2,34}=5,400, p<0,01\right)$, escolhas negativas $\left(F_{2,34}=3,273, p<0,05\right)$ e a preferência social $\left(F_{2,34}=7,913\right.$, $p<0,01)$. Comparações dois-a-dois através do teste de Tukey revelaram que as crianças avaliadas como pouco atraentes foram alvo de um maior número de escolhas negativas $(p<$ $0,05)$, tenderam a ser alvo de um menor número de escolhas positivas $(p<0,10)$ e apresentaram menor índice de preferência social $(p<0,01)$ em comparação com as julgadas como muito atraentes (Figura 2). Além disso, as consideradas medianamente atraentes foram alvo de um menor número de escolhas positivas $(p<0,01)$ e tiveram índices de preferência social mais baixos $(\phi<0,01)$ do que as tidas como muito atraentes.

O teste de MANOVA não revelou efeito global significativo de sexo nem de interação entre sexo e categorias de atratividade física.

\section{Auto-avaliação de beleza}

Foi detectado efeito multivariado significativo de interação entre auto-avaliação de atratividade física e sexo nos indicadores sociométricos (Lambda de Wilks $=0,804 ; F_{2,30}$ $=3,668 ; p<0,05)$.

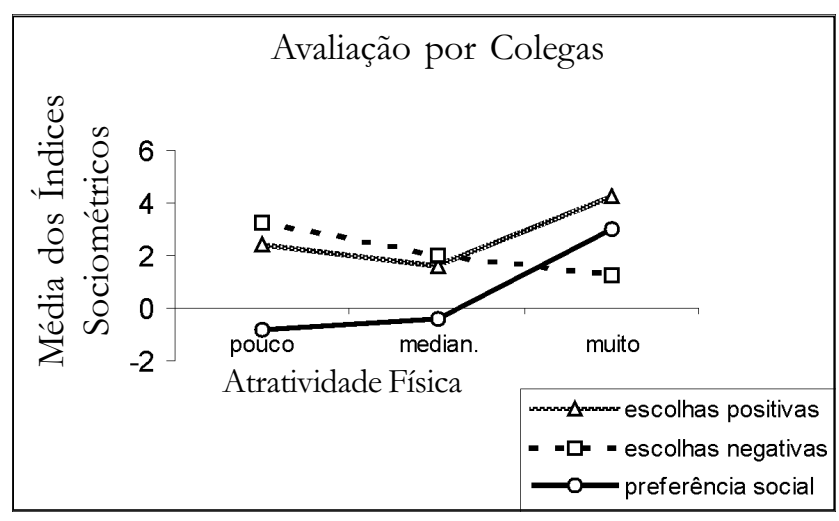

Figura 2. Índices sociométricos em função de atratividade física avaliada pelos colegas.

Testes univariados revelaram efeito significativo sobre as escolhas negativas $\left(F_{1,31}=5,462 ; p<0,05\right)$. As meninas que se consideraram bonitas receberam menor número de escolhas negativas $(2,0 \pm 2,0)$ em comparação com aquelas que se consideraram menos atraentes $(4,5 \pm 0,71)$. Para os meninos essa tendência não foi encontrada. 
Julgamento de Características Comportamentais por Parte de Colegas em Função de Atratividade Física Atratividade Avaliada por Adultos

a) Não familiarizados com as crianças

O teste de MANOVA não revelou efeitos estatisticamente significativos de categorias de atratividade física conforme julgamento por parte de adultos não familiarizados com as crianças sobre os atributos comportamentais.

b) Familiarizados com as crianças

O teste de MANOVA revelou diferença global significativa das características comportamentais atribuídas por colegas em função das categorias de atratividade física avaliada pelos adultos familiarizados com as crianças (Lambda de Wilks $=0,372, F_{16,60}=2,400 p<0,01$ ). Testes univariados subseqüentes revelaram diferenças significativas quanto à Não-agressividade $\left(F_{2,37}=6,569, p<0,01\right)$ e quanto à Sociabilidade $\left(F_{2,37}=6,286, p<0,01\right)$. Comparações doisa-dois através do teste de Tukey revelaram que as crianças avaliadas como muito atraentes foram consideradas menos agressivas e mais sociáveis do que as vistas como pouco atraentes $(p<0,01)$. Já as crianças apreciadas como muito atraentes, quando comparadas às percebidas como medianamente atraentes, foram julgadas como mais sociáveis $(p<0,05)$ e tenderam a ser avaliadas como menos agressivas $(p=0,06)$. A Figura 3 apresenta as médias dos diversos parâmetros comportamentais em função da atratividade conforme avaliação de adultas familiarizadas com as crianças.

\section{Atratividade Avaliada pelos Colegas}

O teste de MANOVA revelou diferença global significativa dos atributos comportamentais em função das categorias de atratividade física avaliada pelos colegas (Lambda de Wilks $\left.=0,283, F_{16,60}=3,300, p<0,001\right)$. Testes univariados subseqüentes revelaram diferenças significativas quanto a

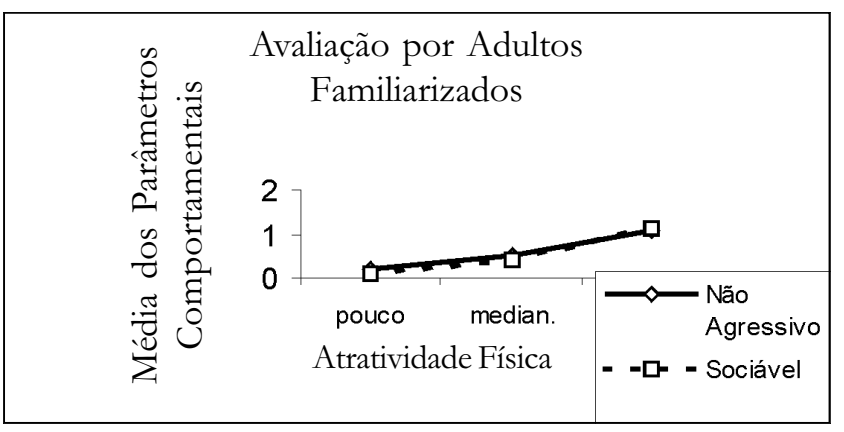

Figura 3. Parâmetros comportamentais em função de atratividade física avaliada por adultos familiarizados. características comportamentais positivas - Colaboração $\left(F_{2,37}=3,788, p<0,05\right)$, Alegria $\left(F_{2,37}=5,446, p<0,01\right)$, Não-agressividade $\left(F_{2,37}=9,682, p<0,001\right)$ e Sociabilidade $\left(F_{2,37}=9,343, p<0,01\right)-$ e negativas: Comportamento Perturbador $\left(F_{2,37}=7,919, p<0,01\right)$, Tristeza $\left(F_{2,37}=7,894\right.$, $p<0,01)$, Agressividade $\left(F_{2,37}=3,419, p<0,05\right)$ e Isolamento Social $\left(F_{2,37}=3,727, p<0,05\right)$. Comparações dois-a-dois através do teste de Tukey revelaram que as crianças consideradas pouco atraentes, em relação às julgadas como muito atraentes, foram avaliadas como menos sociáveis, mais isoladas, mais agressivas $(\phi<0,05)$ e mais perturbadoras $(p<0,01)$. Com relação às crianças percebidas como medianamente atraentes, as consideradas pouco atraentes foram avaliadas como mais agressivas, mais tristes, mais perturbadoras $(p<0,01)$ e mais isoladas $(p<0,05)$. Já as crianças tidas como muito atraentes foram avaliadas como mais colaboradoras, mais alegres $(p<0,05)$, menos agressivas e mais sociáveis $(p<0,01)$ do que as vistas como medianamente atraentes. A Figura 4 mostra as médias das características comportamentais atribuídas por colegas em função de atratividade física.
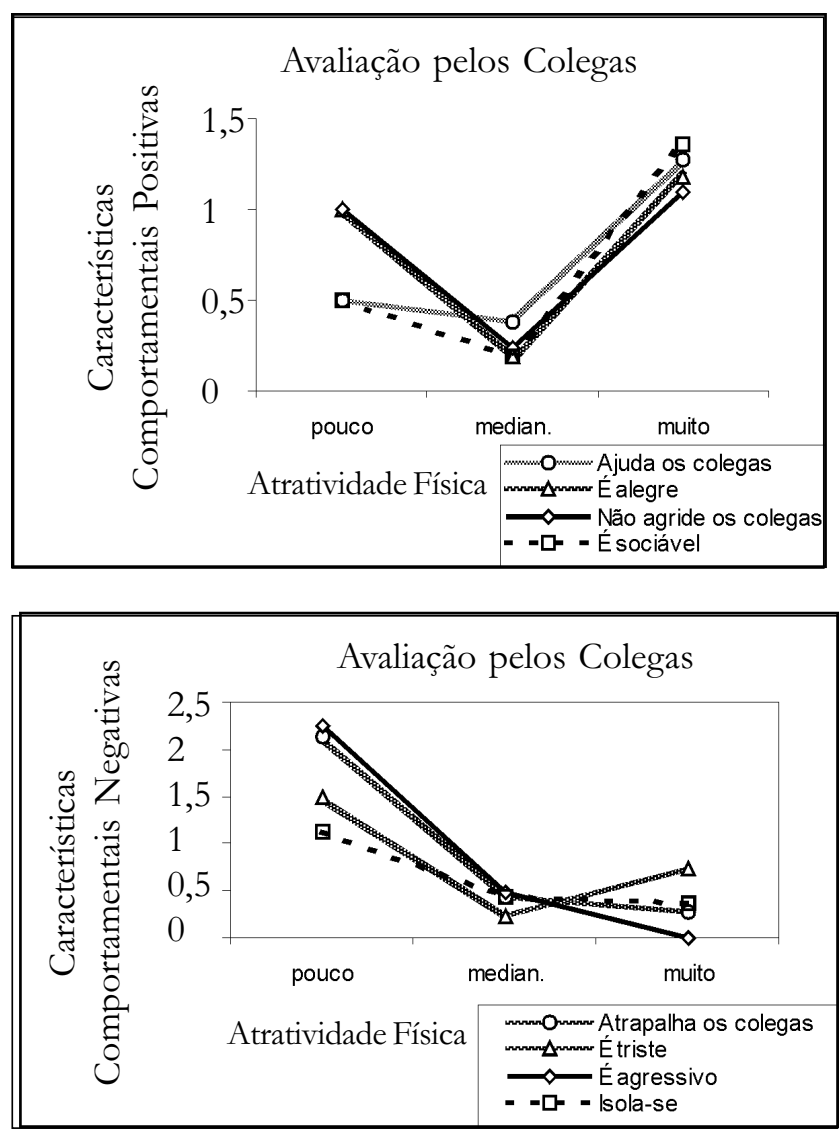

Figura 4. Parâmetros comportamentais positivos e negativos em função de atratividade física avaliada pelos colegas. 
Auto-avaliação de beleza

Não foi detectado efeito multivariado significativo do julgamento de características comportamentais por parte dos colegas em relação à auto-avaliação de atratividade física.

\section{Competência e Aceitação Social Percebidas em Função de Atratividade Física}

Encontrou-se efeito multivariado significativo da autoavaliação de atratividade física sobre os escores obtidos através da Escala Ilustrada de Competência e Aceitação Social Percebidaspara Criancas de Harter e Pike $(1980,1983)$ (Lambda de Willes $\left.=0,706, F_{4,30}=3,125, p<0,05\right)$. Análises univariadas revelaram efeitos significativos para Aceitação por Companheiros $\left(F_{1,33}=8,527, p<0,01\right)$, Aceitação Materna $\left(F_{1,33}=7,477, p<0,01\right)$, Competência Física $\left(F_{1,33}=5,317\right.$, $p<0,05)$ e Competência Cognitiva $\left(F_{1,33}=7,959, p<0,01\right)$. A Tabela 3 mostra que as crianças que se auto-avaliaram como atraentes também se consideraram mais aceitas pelos companheiros e pela mãe e se perceberam como mais competentes física e cognitivamente do que as que se avaliaram como medianamente atraentes.

Não foram encontrados efeitos das avaliações de atratividade física por parte de adultos não familiarizados, adultos familiarizados, nem de colegas sobre os escores obtidos através da EICASP.

\section{Relações entre Avaliações de Atratividade Física e a Classificação de Raça/ cor/etnia da Criança}

Para verificar se diferenças nas avaliações de atratividade estavam associadas a cor/raça/etnia, utilizaram-se testes de qui-quadrado. As avaliações dos colegas não foram influenciadas pela variável cor/raça/etnia, ou seja, a distribuição de brancos e pretos/pardos nas três categorias de atratividade (muito, medianamente e pouco atraentes) conforme avaliação dos colegas, não apresentou diferenças estatisticamente significativas. Nesta análise, o parâmetro utilizado foi a subtração do número de citações como menos atraente do número de citações como mais atraente.
Efetuamos uma análise adicional através do teste de qui-quadrado, para verificar se haveria uma tendência para as crianças considerarem mais atraentes colegas da mesma cor/raça/etnia e, para isso, registrou-se para cada sujeito qual foi a raça do colega nomeado como mais atraente. Novamente, nenhuma relação significativa foi encontrada.

No caso das juízas adultas, foram encontrados resultados significativos, indicando que mais crianças brancas foram avaliadas como atraentes do que pretas/pardas tanto pelas juízas estranhas $\left(X^{2}=12,40 ; g l=4 ; p<0,05\right)$ como pelas familiarizadas $\left(X^{2}=16,47 ; g l=4 ; p<0,01\right)$.

\section{Discussão}

Nossos resultados indicam que os julgamentos de atratividade foram afetados pelas características comportamentais das crianças analisadas. Embora as avaliações de atratividade dos adultos não familiarizados estivessem correlacionadas com as dos adultos familiarizados e a desses últimos com as avaliações dos colegas, chama a atenção a não-transitividade, ou seja, a ausência de correlação significativa entre adultos não familiarizados e colegas. É possível considerar que o elemento familiarização aproximou mais as avaliações de adultos que conheciam as crianças. Pode-se supor que os julgamentos de atratividade feitos nesses casos tenham sido também afetados pelas características comportamentais das crianças avaliadas.

Por sua vez, a correlação entre os adultos, independentemente da familiarização, poderia decorrer de efeitos mais ligados a fatores estritamente estéticos, ainda atuando nos adultos familiarizados, e que poderiam estar amenizados no grupo de colegas, para os quais a familiarização seria preponderante. Alternativamente, poderse-ia pensar em pontos de vista comuns decorrentes do fato dos juízes serem todos adultos. Entretanto, seja como for, o fator etário parece não ter sido suficiente para impedir a correlação entre adultos familiarizados e crianças.

A ausência de efeito da variável cor/raça/etnia sobre os julgamentos de atratividade por parte dos colegas reforça a

Tabela 3

Médias e Erros-Padrão dos Escores Obtidos Através da EICASP em Função de Auto-Avaliação de Atratividade Física

\begin{tabular}{|c|c|c|c|c|}
\hline & \multicolumn{2}{|c|}{$\begin{array}{c}\text { Medianamente } \\
\text { atraentes }\end{array}$} & \multicolumn{2}{|c|}{$\begin{array}{c}\text { Muito } \\
\text { atraentes }\end{array}$} \\
\hline & $m$ & $E P$ & $m$ & $E P$ \\
\hline Aceitação por companheiros & 2,67 & 0,16 & 3,24 & 0,11 \\
\hline Aceitação materna & 2,64 & 0,15 & 3,16 & 0,11 \\
\hline Competência física & 3,18 & 0,10 & 3,52 & 0,07 \\
\hline Competência cognitiva & 3,28 & 0,08 & 3,51 & 0,06 \\
\hline
\end{tabular}


suposição de predomínio do efeito das características comportamentais sobre tais julgamentos. Podemos supor ou que as crianças não tenham ainda assimilado da cultura os estereótipos associados à cor da pele e a características de raça/etnia, ou que a familiaridade e a convivência tenham atenuado seu efeito. O presente trabalho aponta na direção da suposição de que, para crianças pequenas o peso da variável atratividade é maior do que o da cor/raça/etnia. Estes dados são parcialmente reforçados pelo estudo de Langlois e Stephan (1977), que sugerem que "os estereótipos associados à atratividade física são determinantes mais fortes da preferência por companheiros e de atribuições de características comportamentais do que os estereótipos étnicos" (p. 1694).

Verificamos que as juízas, todas mulheres brancas, consideraram mais atraentes as crianças de sua cor. Embora reconheçamos que a opinião de adultos seja um dos fatores que podem influenciar as relações criança/criança, não nos estenderemos na discussão do fenômeno de estereótipos de cor/ raça/etnia em adultos, por não se tratar do escopo do presente trabalho, cujo foco foi direcionado para a interação entre as crianças. Consideramos, contudo, que a presença de estereótipos revelada nas escolhas das juízas adultas é um dado tão relevante que requer estudos específicos, em que seja considerado o julgamento de homens e mulheres de diferentes etnias, em maior número, com diferentes graus de convivência com as crianças e dentro dos diversos segmentos sociais.

As adultas não familiarizadas foram as únicas a avaliarem fotos. $O$ fato de, ainda assim, haver correlação com a avaliação das adultas familiarizadas reforça a possibilidade de efeitos estritamente estéticos. Contudo, não se deve desprezar a possibilidade de as fotos retratarem, em algum nível, índices de ajustamento comportamental, que poderiam, intuitivamente, estar sendo utilizados no processo de avaliação, ainda mais se considerarmos que os julgamentos foram baseados em duas fotos das crianças, uma com a face séria e a outra com a face sorridente.

O rosto revela para o outro muitas informações sobre interesse, motivação, disponibilidade. Informações baseadas na pupila, um mero detalhe no conjunto possível do rosto, ajudam a ilustrar essa idéia. Estudos clássicos a partir da descoberta de Hess $(1965,1975)$ sobre a relação entre interesse e dilatação da pupila, mostram que fotos com pupilas artificialmente dilatadas são julgadas como sendo mais atraentes, mais amistosas e mais confiáveis, ainda que os juizes não tenham consciência do que os levou a esse julgamento (Stass \& Willis, 1967). Além de informações sobre estados passageiros, é possível também que existam na aparência indicadores de personalidade, porque certos traços característicos e sistemáticos marcam de muitas maneiras a aparência da pessoa (Andersen, 1999; Ectoff, 1999). Os “instantâneos comportamentais" apresentados nas fotografias, sem dúvida, revelaram também indícios da expressividade das crianças e foram supostamente considerados na avaliação dos adultos não familiarizados.

A ligação entre julgamentos comportamentais, de preferência social e de atratividade física foi confirmada na segunda e terceira partes dos resultados obtidos em nossa pesquisa. Os colegas indicados como sendo aqueles que mais ajudavam, menos agrediam, e que eram mais sociáveis e mais alegres foram também indicados como os considerados mais apreciados e os mais bonitos. Note-se que o procedimento era iniciado pela apresentação de figuras de crianças em ação, sempre ajudando ou sempre atrapalhando, sempre sociáveis ou sempre isoladas, e assim por diante, pedindo-se para o sujeito indicar quem da classe se parecia com elas, dentre os 40 colegas. As figuras remetiam a ações concretas de ajudar, atrapalhar, agredir, não agredir, ser sociável, ficar isolada e mostrar-se alegre ou triste.

Os resultados denotam ligações entre afeto, julgamento de atratividade e avaliações comportamentais bem estabelecidas em crianças de 5 anos. Para explicar essa associação, a literatura tem salientado como essencial o efeito do estereótipo da beleza. A meta-análise feita por Feingold (1992) concluiu que pessoas consideradas atraentes não são necessariamente o que parecem ser, apontando para o efeito de halo da beleza, baseando-se no fato dessas pessoas tenderem a ser percebidas por jovens e adultos como mais sociáveis, dominantes, saudáveis, inteligentes e socialmente habilidosas, embora tenham sido encontradas correlações baixas entre atratividade e medidas de personalidade e de capacidade mental. Feingold levantou a possibilidade de as correlações reais serem derivadas do estereótipo de beleza: possíveis diferenças comportamentais entre pessoas atraentes e não atraentes ou seriam enganos, ou seriam sub-produto desses enganos, gerados pelos processos descritos nos modelos de expectativa/profecia auto-realizadora (Harris \& Rosenthal, 1985). Tais processos levariam à confirmação da expectativa criada pela impressão inicial, que é, em grande medida, determinada por estereótipos. Contudo, para que se possa avaliar o real efeito dos estereótipos são necessários estudos complementares que possam aferir as características que são associadas às crianças em função de sua aparência física por juizes que não as conhecem. O melhor conhecimento do processo que leva à atribuição de certas características positivas às crianças mais atraentes contribuirá também para a compreensão e prevenção (na escola, por exemplo) dos efeitos que têm os estereótipos e as expectativas na avaliação e controle do comportamento do outro. 
O temor dos efeitos perniciosos dos preconceitos e estereótipos tem nos impedido de considerar que os erros de avaliação são facetas de um processo humano de reconhecimento e de avaliação do outro, que precisa ser mais bem entendido. Tem também restringido as interpretações sobre a beleza como limitada a essa classe de fenômenos, embora existam razões para supormos tratar-se de algo fundamental, revelado não só no que é universal no julgamento estético, mas também no que é peculiar nas culturas (Queiroz \& Otta, 1999).

Nem sempre os "enganos" relacionados à autoavaliação de atratividade são danosos. O fato de, na presente pesquisa, as crianças terem apresentado uma autoavaliação de atratividade mais favorável do que a dos demais juizes, dentro desta linha, poderia representar um engano ajustado, adaptativo, no sentido de propiciar uma auto-profecia realizadora mais positiva. Semelhantemente aos dados encontrados neste estudo, Feingold (1992) verificou em sua meta-análise uma correlação baixa de 0,24 entre atratividade física atribuída por juizes externos e auto-avaliação de atratividade física. Analisando a questão do autoconceito em crianças de idade pré-escolar, Harter e Pike (1984) constataram pouca correspondência entre a auto-imagem que a criança tem de si e a imagem que dela têm seus pares, familiares e professores. Esse desacordo levou as autoras a considerarem que a criança, ao se avaliar, confunde, ou, pode-se supor, leva em conta mais sua auto-imagem ideal que a real. A dificuldade da criança pequena em julgar a competência de seu próprio desempenho pode ser adaptativa em alguns contextos. As crianças que superestimam suas próprias habilidades podem experimentar uma maior diversidade de habilidades, deixando de perceber seu desempenho "menos que perfeito" como um fracasso (Bjorklund, 1997; Bjorklund \& Pellegrini, 2000). O único resultado significativo quanto às diferenças entre os sexos refere-se ao menor número de escolhas negativas recebidas pelas meninas que se autoavaliaram como atraentes. A ausência desse efeito nos meninos sugere uma ênfase diferencial desse atributo e traz a necessidade de investigações mais pormenorizadas.

Embora tenhamos razões para atribuir importância para os modelos de estereótipos e de profecia auto-realizadora a partir da beleza, do tipo "quem é bonito é bom”, também devem ser considerados efeitos em sentido oposto, ou seja, características comportamentais positivas ou negativas afetando o julgamento de atratividade, do tipo "quem é bom (e eu gosto) é bonito". No presente trabalho, a concordância de dados entre adultos familiarizados e colegas é sugestiva do efeito da avaliação comportamental sobre o conceito de beleza. $\mathrm{O}$ mesmo pode ser dito da correlação entre suas avaliações de atratividade e de comportamento, especialmente se considerarmos que o procedimento remetia a situações concretas relembradas do cotidiano. Eagly, Ashmore, Makhijani e Longo (1991), em sua meta-análise sobre o estereótipo de atratividade física, ponderam que o efeito "quem é bonito é bom" torna-se menor à medida que aumenta o grau de informações sobre a pessoa que está sendo julgada. O peso de um item de informação como determinante de um julgamento torna-se menor na medida em que um número maior de itens é levado em conta.

É evidente que a análise da relação direta com o comportamento exigiria a consideração de dados de observação de comportamento, que será futuramente realizada, como parte de um estudo mais amplo que está em andamento.

Ao dizer que efeitos de halo podem ocorrer nos dois sentidos, pode-se ficar tentado a encarar os processos, nos dois casos, como decorrentes de viés. Embora as duas coisas sejam possíveis, convém salientar que a aparência pode efetivamente revelar o ajustamento, caso em que as avaliações não deveriam ser consideradas como enganos estereotipados, mas sim como avaliações justificadas. Somos atraídos por um composto que julgamos belo, mas que pode ser constituído por sinais que vão além do estritamente estético, especialmente se este estritamente estético for entendido como algo anatômico e independente de fatores psicológicos. É muito provável que sejamos especialmente sensíveis para indicadores de ajustamento que podem transparecer na aparência. Nos estudos de beleza dentro do contexto de atração sexual, há indicadores da correlação entre determinados traços de beleza com a percepção de saúde reprodutiva (Queiroz \& Otta, 1999; Shackelford \& Larsen, 1999; Singh, 1993). De modo análogo, poderse-ia pensar na ligação entre alguns traços de beleza percebida com ajustamento psicológico. A atratividade abordada num sentido mais amplo - ou seja, também como indicador de ajustamento psicossocial - dá sinais que servem como pistas para o reconhecimento do indivíduo pelos parceiros da interação, servindo assim como elemento mediador das relações em grupo.

Há um acordo entre os teóricos da evolução humana sobre as condições de evolução da inteligência e da consciência no homem, apontando para a importância da vida em grupo e da formação de alianças como força seletiva essencial (Lewin, 1998/1999): o próprio crescimento cortical estaria associado à aquisição dessas habilidades. Tudo indica que grande parte da pressão seletiva que tornou o ser humano o que ele é girou em torno de possibilitar regulações sociais recíprocas. Evidência notável dessa hipótese é encontrada nas capacidades expressivas e de regulação recíproca por 
sincronização e espelhamento de expressões apresentadas por recém-nascidos (Bussab \& Ribeiro, 1998). A preferência dos bebês por faces consideradas atraentes por adultos (Langlois \& cols., 1991; Langlois \& cols., 1987; Slater \& cols., 1998) denota, por sua vez, aspectos adaptativos básicos do julgamento estético. A presença das associações entre afeto, atratividade e julgamentos de comportamento nas crianças de cinco anos do presente estudo reafirma esse processo como essencial ao relacionamento humano e reitera a importância de sua compreensão.

\section{Referências}

Adams, G. R. \& Crane, P. (1980). An assessment of parents' and teachers' expectations of preschool children's social preference for attractive or unattractive children and adults. Child Development, 51, 224-231.

Attili, G. (1990). Successful and disconfirmed children in the peer group: Indices of social competence within an evolutionary perspective. Human Development, 33, 238-249.

Andersen, P. A. (1999). Nonverbal communication: Forms and functions. Mountain View, California: Mayfield.

Berger, C. R. \& Calabrese, R. J. (1975). Some explorations in initial interaction and beyond: Toward a theory of interpersonal communication. Human Communication Research,1, 99-112.

Bjorklund, D. F. (1997). The role of immaturity in human development. Psychological Bulletin, 122, 153-169.

Bjorklund, D. F. \& Pellegrini, A. D. (2000). Child development and evolutionary psychology. Child Development, 71, 1687-1708.

Brown, R. W. (1986). Social Psychology. New York: Free Press.

Bussab, V. S. R. \& Ribeiro, F. J. L. (1998). Biologicamente cultural. Em L. Souza, M. F. Q. Freitas \& M. M. P. Rodrigues (Orgs.), Psicologia: Reflexões (im)pertinentes (pp. 175-193). São Paulo: Casa do Psicólogo.

Cavior, N. \& Howard, L. R. (1973). Facial attractiveness and juvenile delinquency among black and white offenders. Journal of Abnormal Child Psychology, 1, 202-213.

Chia, R. C., Allred, L. J., Grossnickle, W. F. \& Lee, G. W. (1998). Effects of attractiveness and gender on the perception of achievement-related variables. The Journal of Social Psychology, 138, 471-477.

Coie, J. D., Dodge, K. A. \& Coppotelli, H. (1982). Dimensions and types of social status: A cross-age perspective. Developmental Psychology, 18, 557570.

Darley, J. M. \& Fazio, R. H. (1980). Expectancy confirmation processes arising in the social interaction sequence. American Psychologist, 35, 867-881.

Dermer, M. \& Thiel, D. L. (1975). When beauty may fail. Journal of Personality and Social Psychology, 31, 1168-1176.

Dion, K. K. (1972). Physical attractiveness and evaluations of children's transgressions. Journal of Personality and Social Psychology, 24, 207-213.

Dion, K. K. (1974). Children's physical attractiveness and sex as determinants of adult punitiveness. Developmental Psychology, 10, 772-778.

Dion, K. K., Bescheid, E. \& Walster, E. (1972). What is beautiful is good. Journal of Personality and Social Psychology, 24, 285-290.

Eagly, A. H., Ashmore, R. D., Makhijani, M. G. \& Longo, L. C. (1991). What is beautiful is good, but ...: A meta-analytic review of research on the physical attractiveness stereotype. Psychological Bulletin, 110, 109-128.

Ectoff, N. (1999). A lei do mais belo: A ciência da beleza (A. L. B. Barros, Trad.). Rio de Janeiro: Objetiva. (Original publicado em 1999)

Feingold, A. (1992). Good looking people are not what we think. Psychological Bulletin, 2, 304-341.

Franco, N. \& Levitt, M. J. (1998). The social ecology of middle childhood: Family support, friendship quality and self-esteem. Family Relations, 47, 315-321.
Furnham, A. (1989). Friendship and personal development. Em R. Porter \& S. Tomaselli (Orgs.), The dialectics of friendship (pp. 92-110). London: Routledge.

Guimarães, A. S. A. (2000). Apresentação. Em A. S. A. Guimarães \& L. Huntley (Orgs.), Tirando a máscara: Ensaios sobre o racismo no Brasil (pp. 17-30). São Paulo: Paz e Terra.

Harris, M. J. \& Rosenthal, R. (1985). Mediation of expectancy effects: 31 meta-analyses. Psychological Bulletin, 97, 363-386.

Harter, S. (1999). The construction of the self: A developmental perspective. New York: The Guilford Press.

Harter, S. \& Pike, R. (1980). The Pictorial Scale of Perceived Competence and Social Acceptance for Young Children. Plates: Preschool and kindergarten, male and female. Colorado: University of Denver.

Harter, S. \& Pike, R. (1983). The Pictorial Scale of Perceived Competence and Social Acceptance for Young Children. Procedural manual. Colorado: University of Denver.

Harter, S. \& Pike, R. (1984). The Pictorial Scale of Perceived Competence and Social Acceptance for Young Children. Child Development, 55, 1969-1982.

Hatzichristou, C. \& Hopf, D. (1996). A multiperspective comparison of peer sociometric status groups in childhood and adolescence. Child Development, 67, 1085-1102.

Hess, E. H. (1965). Attitude and pupil size. Scientific American, 212, 46-54.

Hess, E. H. (1975). The role of pupil size in communication. Scientific American, 233, 110-119.

Kleck, R., Richardson, S. A. \& Ronald, L. (1974). Physical appearance cues and interpersonal attraction in children. Child Development, 45, 305-310.

Knapp, M. L. \& Hall, J. A.(1972 / 1999). Comunicação não-verbal na interação bumana (M. A. L. Barros, Trad.). São Paulo: JSN Editora. (Original publicado em 1972)

Langlois, J. H. \& Stephan, C. (1977). The effects of physical attractiveness and ethnicity on children's behavioral attributions and peer preferences. Child Development, 48, 1694-1698.

Langlois, J. H., Ritter, J. M., Roggman, L.A. \& Vaughn, L. S. (1991). Facial diversity and infant preferences for attractive faces. Developmental Psychology, 27, 79-84.

Langlois, J. H., Roggman, L. A., Casey, R. J., Ritter, J. M., Rieser-Danner, L. A. \& Jenkins, V. Y. (1987). Infant preferences for attractive faces: Rudiments of a stereotype? Developmental Psychology, 23, 363-369.

Lewin, R. (1999). Evolução bumana (D. Mundord, Trad.). São Paulo: Atheneu. (Original publicado em 1998)

Lopes, V. N. (1999). Racismo, preconceito e discriminação. Em K. Munanga (Org.), Superando o racismo na escola (pp. 183-202). Brasília: Ministério da Educação.

Morais, M. L. S., Otta, E. \& Scala, C. (2001). Status sociométrico e avaliação de características comportamentais: Um estudo de competência social em pré-escolares. Psicologia Reflexão e Crítica, 14, 119-131.

Mussen, P. H., Conger, J. J. \& Kagan, J. (1973). Desarrolo de la personalidad en el niño. México: Trillas.

Parke, R. D., O’Neil, R., Spitzer, S., Isley, S., Welsh, M., Wang, S., Lee, J., Strand, C. \& Cupp, R. (1997). A longitudinal assessment of sociometric stability and the behavioral correlates of children's social acceptance. Merrill-Palmer Quarterly, 43, 635-662.

Queiroz, R. da S. \& Otta, E. (1999). A beleza em foco: Condicionantes culturais e psicobiológicos na definição da estética corporal. Em R. S. Queiroz (Org.), O corpo do brasileiro: Estudos de estética e beleza (pp.1366). São Paulo: SENAC.

Rosenthal, R. \& Jacobson, L. (1968). Pygmalion in the classroom. New York: Holt, Rinehart \& Winston.

Rubin, K. H. (1990). Peer relationships and social skills in childhood - An international perspective: Introduction. Human Development, 33, 221224.

Schneider, D. J. (1973). Implicit personality theories: A review. Psychological Bulletin, 79, 294-309.

Shackelford, T. K. \& Larsen, R. J. (1999). Facial attractiveness and physical health. Evolution and Human Behavior, 20, 71-76. 
Singh, D. (1993). Adaptive significance of female physical attractiveness: Role of waist-to-hip ratio. Journal of Personality and Social Psychology, 65, 293-307.

Slater, A., Von der Schulenburg, C., Brown, E., Badenoch, M., Buttleworth, G., Parsons, S. \& Samuels, C. (1998). Newborn infants prefer attractive faces. Infant Behavior and Development, 21, 345-354.

Stass, W. \& Willis Jr., F. N. (1967). Eye contact, pupil dilatation, and personal preference. Psychonomic Science, 7, 375-376.

Verschueren, K. \& Marcoen, A. (1999). Representation of self and socioemotional competence in kindergarteners: Differential and combined effects of attachment to mother and to father. Child Development, 70, 183-201.
Wheeler, L. \& Kim, Y. (1997). What is beautiful is culturally good: The physical attractiveness stereotype has different content in collectivistic cultures. Personality and Social Psychology Bulletin, 23, 795-800.

Sobre as autoras

Cristina Landgraf Lee-Manoel é Licenciada em Educação Física pela EEFEUSP, Mestre em Ciências do Esporte pela Universidade de Loughborough, Inglaterra e Doutoranda em Psicologia Experimental pelo Instituto de Psicologia da Universidade de São Paulo.

Maria de Lima Salum e Morais é Psicóloga formada pelo IPUSP, com atuação nas áreas de Educação e Saúde Pública, Mestre e Doutoranda em Psicologia Experimental pelo Instituto de Psicologia da Universidade de São Paulo.

Vera Silvia Raad Bussab é Psicóloga formada pelo IPUSP, com atuação na área de Etologia. Professora Doutora do Departamento de Psicologia Experimental do Instituto de Psicologia da Universidade de São Paulo.

Emma Otta é Psicóloga formada pelo IPUSP, com atuação na área de Etologia. Professora Associada, Livre-Docente, Coordenadora do Programa de Pós-Graduação em Psicologia Experimental e Chefe do Departamento de Psicologia Experimental do Instituto de Psicologia da Universidade de São Paulo. 